\title{
Incidence of adrenal gland tumor as a second primary malignancy: SEER-based study
}

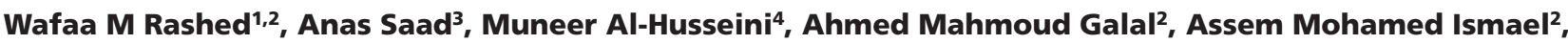 \\ Ahmed M Al-Tayep², Ayman El Shafie ${ }^{2}$, Mahmoud Ahmed Ali² and Ahmad Samir Alfaar ${ }^{5}$
}

${ }^{1}$ Research Department, Children's Cancer Hospital Egypt (CCHE-57357), Cairo, Egypt

${ }^{2}$ Armed Forces College of Medicine, Cairo, Egypt

${ }^{3}$ Faculty of Medicine, Damascus University, Damascus, Syria

${ }^{4}$ Faculty of Medicine, Ain Shams University, Cairo, Egypt

${ }^{5}$ Charité - Universitätsmedizin Berlin, Campus Virchow Klinikum, Ophthalmology Department, Berlin, Germany

Correspondence should be addressed to W M Rashed or A S Alfaar: wafaaanor@gmail.com or ahmadsfar@gmail.com

\begin{abstract}
Purpose: Advances in cancer treatment achieved during the past decades have resulted in increased survival of most pediatric and adult patients that suffered from different adrenal tumor types. This article reviews the incidence and survival of adrenal gland tumors as second primary tumors, according to data from the Surveillance, Epidemiology, and End Results (SEER) database.

Methods: The SEER 13 Registries Database from 1992 to 2013 was used. All primary cancer sites were selected using the multiple primary standardized incidence ratios (MP-SIR) session.

Results: Data for a total of 2,887,468 persons with cancer were reviewed; 117 of whom had suffered second primary adrenal tumors. The overall SIR of adrenal gland tumor as a second primary was 1.5. A high incidence ratio of the event was detected in specific primary tumor sites: hypopharynx (observed/expected $(O / E)=44.6)$; other endocrine tissue (including the thymus) $(\mathrm{O} / \mathrm{E}=38.3)$; small intestine $(\mathrm{O} / \mathrm{E}=8.9)$; liver $(\mathrm{O} / \mathrm{E}=8.7)$; stomach $(\mathrm{O} / \mathrm{E}=5)$; nodal $\mathrm{NHL}(\mathrm{O} / \mathrm{E}=3.8)$; kidney and renal pelvis $(\mathrm{O} / \mathrm{E}=3.2)$ and breast $(\mathrm{O} / \mathrm{E}=1.8)$.

Conclusion: The underlying shared mechanisms should be investigated between adrenal tumors and hypopharyngeal, endocrine and other tumors. Racial disparity is an important challenge in cancer treatment at the United States and should be taken into consideration in the design of cancer prevention programs. This could be achieved through follow-up programs at specialized national cancer networks, especially for rare tumors like adrenal gland.
\end{abstract}

\author{
Key Words \\ - second primary tumor \\ - adrenal gland \\ - SEER \\ - epidemiology
}

Endocrine Connections (2018) 7, 1040-1048

\section{Introduction}

The adrenal gland malignancies are extremely sporadic and heterogeneous. It represents $3.6 \%$ of endocrine glands cancers (1). Adrenal malignancies can be either primary adrenal tumors or secondary metastases, with metastases representing the most common malignant adrenal lesion (2). Most endocrine tumors are benign, but some are malignant (3).

Adrenal malignancies usually occur in the outermost layer of the gland or the adrenal cortex (4). Cancers may occur in both adrenal glands but most commonly only
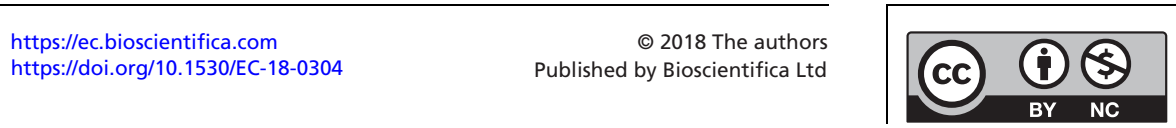
one adrenal gland is affected. Adrenal malignancies can be primary adrenal, second primary malignancies 'SPMs' in cancer survivors or metastatic from other cancer site. Second cancers are a leading cause of morbidity and mortality among cancer survivors. Risk factors for all adrenal gland malignancies are still not well defined (5).

Advances in cancer treatment achieved along the last decades have resulted in increasing the survival in most pediatric and adult cancer types. There has been a significant increase in the number of long-term cancer survivors. Although it is a good news in the fight against cancer, many patients treated with radiation therapy suffer from adverse effects, including the development of a second malignant neoplasm (SMN) (4). We aim to report the incidence of the adrenal gland malignancies as a second primary malignancy based on the Surveillance, Epidemiology, and End Results 'SEER' database.

\section{Patients and methods}

We obtained data from the Surveillance, Epidemiology, and End Results (SEER) program of the US National Cancer Institute, using the SEER*stat software (version 8.3.2). We used the SEER 13 Registries Research Data from 1992 to 2013 . These registries cover approximately $13.4 \%$ of the U.S. population (based on the 2010 census) and include the following registries: San Francisco-Oakland, Connecticut, Detroit, Hawaii, Iowa, New Mexico, Seattle, Utah, Atlanta, San Jose-Monterey, Los Angeles, Rural Georgia as well as Alaska Natives. Morphological ICD-O-3 nomenclature was used for categorizing and presenting tumors. SEER Site recode of Topographical ICD-O-3/ WHO 2008 was used for categorizing the tumor sites. We have calculated the incidence of adrenal gland tumors in general from rate session of SEER*stat program, and then we selected the patients with any 1st primary tumor and followed by 2nd adrenal gland tumors using the multiple primary standardized incidence ratios (MP-SIR) session. An event is defined by the occurrence of a second primary adrenal cancer after any other prior cancer. Also, we calculated SIR of second primary adrenal gland tumor after first primary tumor in relation to 18 age groups in both sexes for age intervals of 5 years till age of 84 then a group of older patients.

\section{Statistical analysis}

In order to exclude the probability of simultaneous cancers; person-years of observation were obtained

$\begin{array}{lr}\text { https://ec.bioscientifica.com } & \text { ○ } 2018 \text { The authors } \\ \text { https://doi.org/10.1530/EC-18-0304 } & \text { Published by Bioscientifica Ltd }\end{array}$

2 months after the time of diagnosis of the primary cancers. We also examined the exposure to radiation as one of the treatment modalities used for the treatment of the first primary tumor, and its possible impact on the development of a subsequent adrenal gland tumor.

We calculated the observed-to-expected $(\mathrm{O} / \mathrm{E})$ ratios of second primary adrenal cancers, with 95\%CIs. We first calculated the overall $(\mathrm{O} / \mathrm{E})$ ratio, and then we stratified the results according to the first primary malignancy site, the latency between the two diagnoses and prior exposure to radiation. A positive association was defined as the number of observed cases being more than the number of expected cases in the general population. The expected number of adrenal cancers cases was based on population data from USA census data connected to the SEER database. We used the Kaplan-Meier test to calculate the overall survival starting from the date of the diagnosis of the second primary adrenal cancer. We excluded the case with two subsequent adrenal cancer events from survival analysis. IBM SPSS Software, version 20 was used for calculation of both frequency and survival. A $P$ value less than 0.05 was considered significant, with no correction made for multiple significance testing.

\section{Results}

Generally, adrenal gland tumors showed an agestandardized incidence of 3.1 per million (2765 patients) with bimodal distribution of 4.0 per million in the age group 0-19 years, 1.3 in the group 20-49 years and 5.0 in the age group older than 50 years.

Data of a total of $2,887,468$ persons with cancer were reviewed, 117 of whom had suffered second primary adrenal tumors. One of these 117 patients had two events of adrenal cancers as a second primary, making the total number of events 118 incidences.

\section{Demographics and clinical characteristics}

The sequence of the subsequent adrenal cancer was the second in most cases (84.6\%) (Table 1). Mean age (in years) at event (the diagnosis of second primary adrenal cancer) was $66.8 \pm 14.3$ (median=68.00). Patients' ages ranged between 1 and 98 years. There were 87 patients (74.4\%) who suffered second primary adrenal gland tumors at older than 60 years of age. But SIR for patients below 60 years was considerably higher than that for older patients ( $\geq 60$ years). Also, we noted that SIR for 
Table 1 The characteristics and standardized incidence ratios (SIR) of patients of second primary adrenal gland tumor.

\begin{tabular}{|c|c|c|}
\hline Characteristic & No $(\%)$ & SIR $(95 \% \mathrm{CI})$ \\
\hline \multicolumn{3}{|l|}{ Age (years) } \\
\hline$<60$ & $30(25.6)$ & $1.6(1.2-2.2) *$ \\
\hline$\geq 60$ & $87(74.4)$ & $1.4(1.1-1.8)^{*}$ \\
\hline \multicolumn{3}{|l|}{ Sex } \\
\hline Male & $61(52.1)$ & $1.4(1.1-1.8)^{*}$ \\
\hline Female & 56 (47.9) & $1.6(1.2-2.1)^{*}$ \\
\hline \multicolumn{3}{|l|}{ Race } \\
\hline White & $103(88.0)$ & $1.53(1.3-1.9) *$ \\
\hline Black & $12(10.3)$ & $2.1(1.1-3.5)^{*}$ \\
\hline Asian or Pacific Islander & $2(1.7)$ & $0.5(0.1-1.7)$ \\
\hline \multicolumn{3}{|l|}{ Sequence } \\
\hline Second & 99 (84.6) & \\
\hline Third & 17 (14.5) & \\
\hline Fourth & $1(0.9)$ & \\
\hline
\end{tabular}

* Significant value at $P<0.05$

SIR, standardized incidence ratio.

females was considerably higher than that for males. The characteristics of patients who had second primary adrenal gland tumors are summarized in Table 1.

Also, we noted a high percentage of white patients (88\%) who had suffered an event compared with other races (12\%) (blacks, Asians or Pacific Islanders). But SIR for black race patients was higher than that for white race patients.

Out of the 13 registries reviewed, there were no reported events in the Alaska Native registry while the biggest percentage of patients with events reported were from the Los Angeles registry (16.2\%). Although the adrenal gland is a paired site, the most reported tumors were from the left side (51.3\%), followed by the right side (39.3\%). There were $7.7 \%$ of cases with no information about laterality and $1.7 \%$ of bilateral single primary.

Adenocarcinomas (codes 8140-8389) represented the most frequent histology in those patients $(n=67,56.8 \%)$ followed by epithelial neoplasms and paragangliomas (16.1\% and $12.7 \%$ respectively). Other unspecified, neuroepitheliomatous and soft-tissue neoplasms represented the rest of the tumors.

Only four patients of adrenal gland tumor diagnosis suffered a primary and a second primary tumor of the same histology (8370/3: adrenal cortical carcinoma). Also, we found two patients who had two odd histology subtypes of adrenal gland tumors as second primary cancers (clear cell adenocarcinoma, NOS (8310/3) and renal cell carcinoma $(8312 / 3))$.

Both female breast (27 cases, $23.1 \%$ ) and prostate (22 cases, $18.8 \%$ ) were the most frequent primary cancer sites that preceded an event.

\section{Overall incidence}

The overall SIR of adrenal gland tumors as second primaries was higher than expected $(\mathrm{O} / \mathrm{E}=1.5$, 95\% CI $=1.2-1.8$ ) (Table 2). When divided according to age groups, the highest increase in risk was in these three groups: 35-39, 50-54 and 65-69 (Fig. 1). Examining the incidence of events in relation to first primary tumor site showed significantly higher incidences in specific sites (Table 2) including the hypopharynx $(\mathrm{O} / \mathrm{E}=44.6$, 95\% CI=9.2-130.4); other endocrine tissue (including the thymus and excluding thyroid $)(\mathrm{O} / \mathrm{E}=38.3,95 \% \mathrm{CI}=$ 10.4-98.1); the small intestine $(\mathrm{O} / \mathrm{E}=8.9,95 \% \mathrm{CI}=$ 1.1-32); the liver $(\mathrm{O} / \mathrm{E}=8.7,95 \% \quad \mathrm{CI}=1.1-31.6)$; the stomach $(\mathrm{O} / \mathrm{E}=5,95 \% \mathrm{CI}=1-14.5)$; nodal $\mathrm{NHL}$ $(\mathrm{O} / \mathrm{E}=3.8,95 \% \mathrm{CI}=1.5-7.8)$ and the kidneys and renal pelvis $(\mathrm{O} / \mathrm{E}=3.2,95 \% \mathrm{CI}=1.2-6.9)$. Breast cancers were also followed by significantly high incidences of adrenal tumor events $(\mathrm{O} / \mathrm{E}=1.8,95 \% \mathrm{CI}=1.2-2.6)$. Interestingly, 15 cases of second primary adrenal tumors were pheochromocytomas; two of them were preceeded by prostate cancer.

\section{Latency}

The median time in months between the diagnosis of 1 st and the following primary cancers was 38.0 months. The range was from 2.0 to 196.0 months. Table 2 shows $\mathrm{O} / \mathrm{E}$ ratios in relation to latent periods between second primary adrenal gland tumors and first primary tumors. In total, there was a high incidence of events recorded in the registry in the periods between 2-12 months and 1-4 years following the first primary tumor. Although the highest observed number of events was in the period between 1 and 4 years, but the O/E ratio was the highest at 2-12 months after the first primary tumor diagnosis.

\section{Radiation}

Overall, exposure to radiation was not associated with an increased risk for the development of an adrenal cancer. However, when data were stratified according to the sites of the first cancers, some sites showed increased risk with radiation exposure. (Table 2 ).

\section{Survival}

The median survival was 14 months with a standard error of 4.2 (95\% CI 5.8-22.2) (Fig. 2).

This work is licensed under a Creative Commons Attribution-NonCommercial 4.0 International License. 


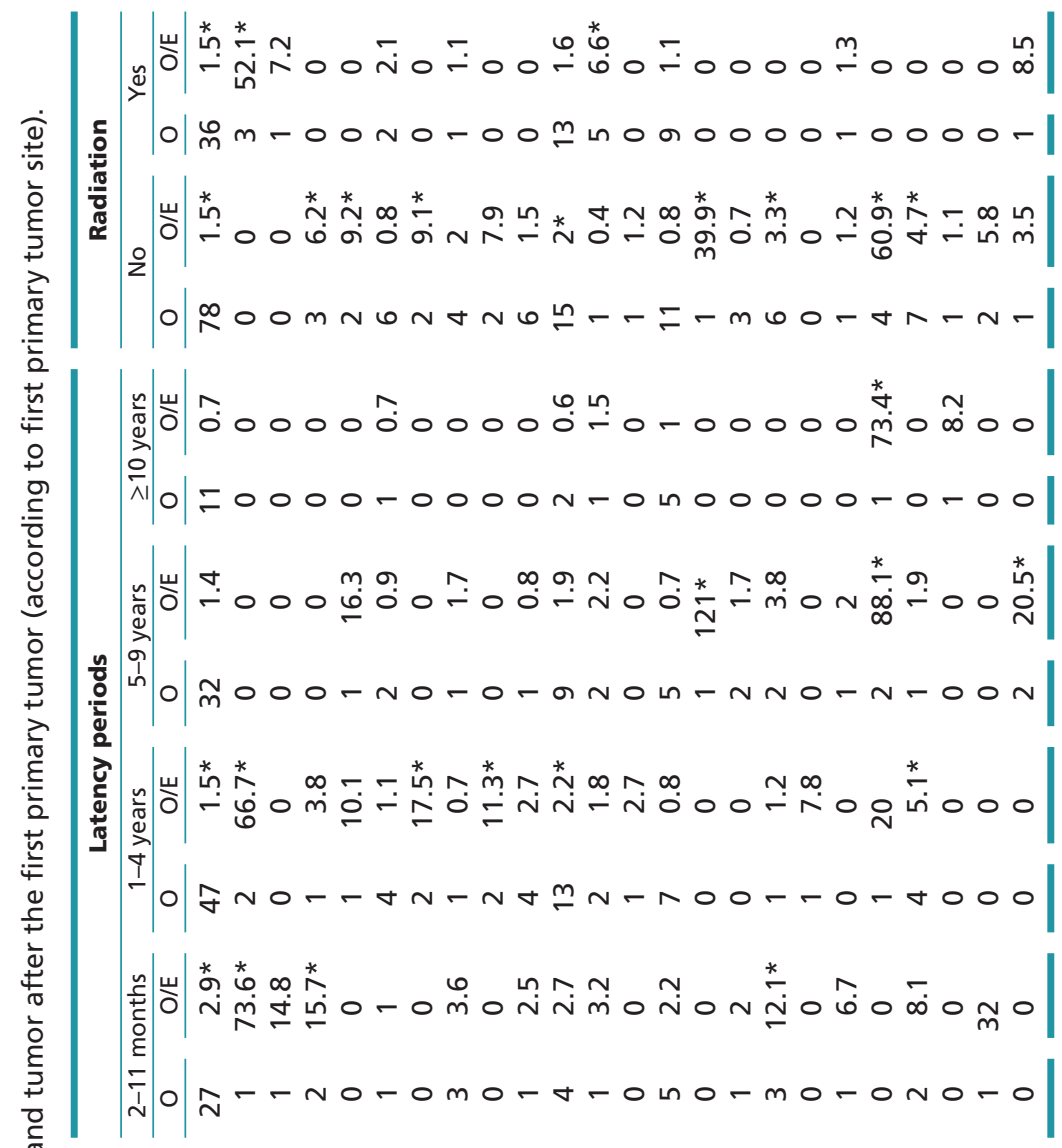

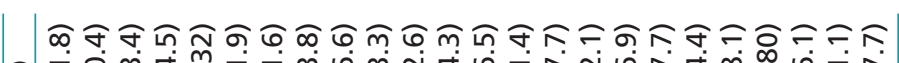

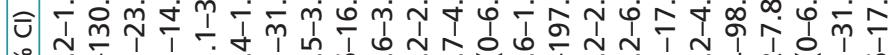

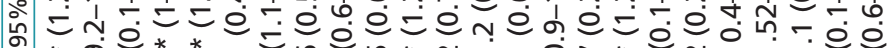

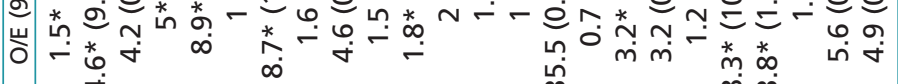

ฮึ \& $\stackrel{\infty}{m} \stackrel{\infty}{m}$

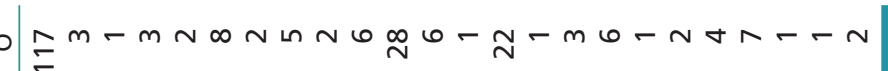

丩

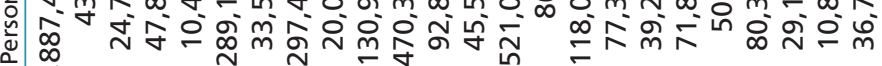

i
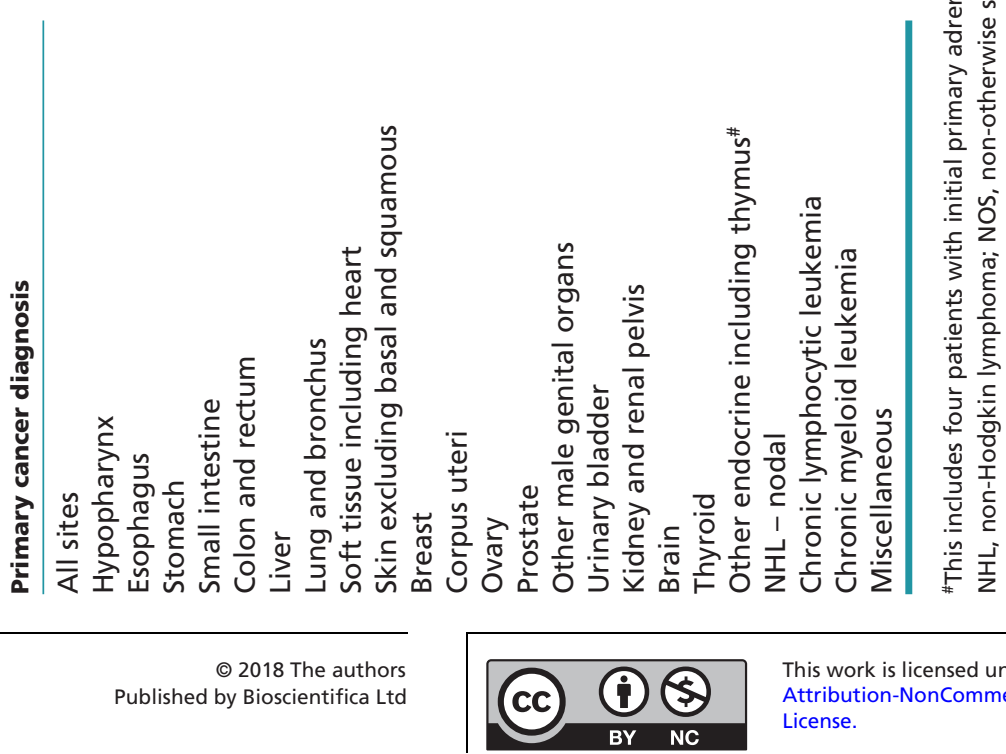

This work is licensed under a Creative Commons Attribution-NonCommercial 4.0 International License. 


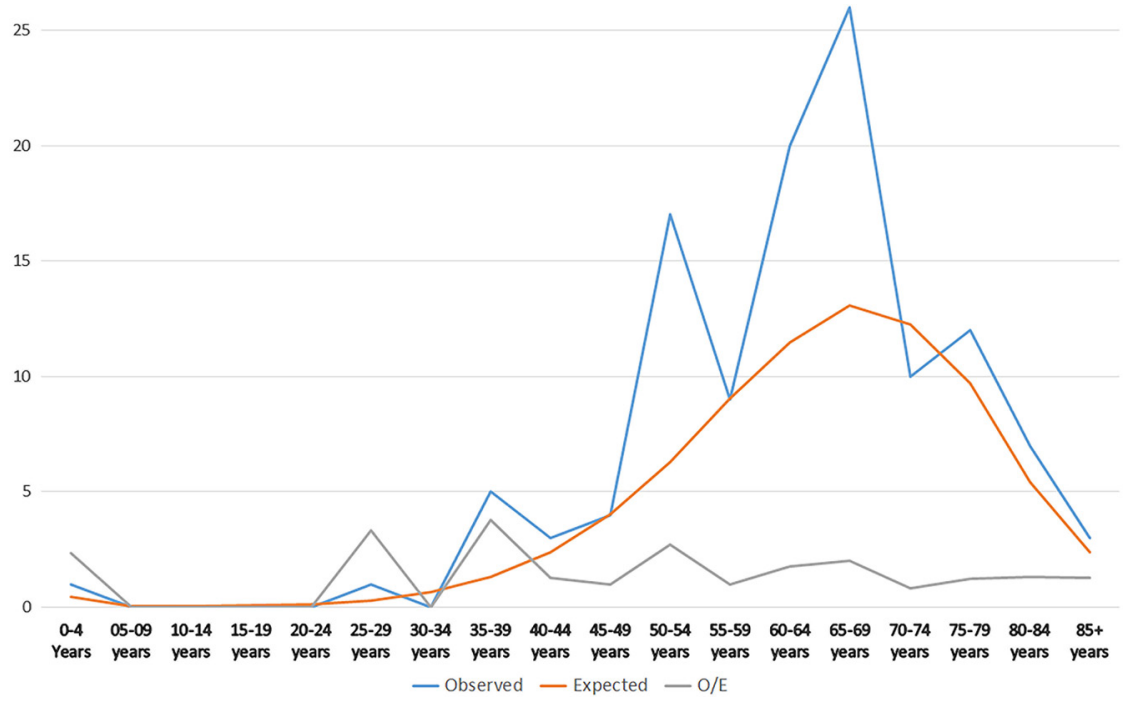

\section{Figure 1}

Observed, expected and standardized incidence ratios of second primary adrenal gland tumors by age groups. Age groups (35-39), (50-54) and $(65-69)$ are of significant difference $(P<0.05)$.

\section{Discussion}

Tumors of adrenal gland are classified into those arising from the cortex or medulla and metastatic ones from known primary origin or unknown origin. Most common adrenal gland malignancies were as a metastasis from other sites. The most common primary cancer sites of metastasis to adrenal gland are breast carcinoma, melanoma, lung cancer, colon tumor and renal cell carcinoma (6). No information in literature is available about adrenal gland malignancies as second primaries. The conduct of quantitative studies for second malignancy in cancer survivors implicates alert to clinicians for the importance of medical surveillance of cancer survivors (7). Moreover, this is helpful to clarify the role of antecedent treatment, shared risk factors, shared genetic abnormality and other etiological influences (8).

Laterality and histology trends found in second primary malignancies were similar to trends shown by first primary adrenal malignancies (these data were obtained from SEERstat but not shown).

We found that there is significant high incidence of adrenal gland malignancies among previous cancer survivors. The reason behind this may be that the previous cancers themselves increased the risk, their treatment did or both the first and second cancers had the same risk factors. We do not have sufficient data to reach a conclusion considering this point.

The overall SIR of adrenal gland malignancies as a second primary malignancy was 1.48 . High percent of these events were found in elder patients especially those of white race. High incidence of the event was detected in specific primary tumor sites: hypopharynx, stomach, small intestine, liver, breast, kidney and renal pelvis, other endocrine including thymus and nodal NHL. The association of adrenal gland tumors and some other cancers should be taken with caution as the absolute number is small, and it needs further longitudinal studies and more detailed analysis. The positive significance with

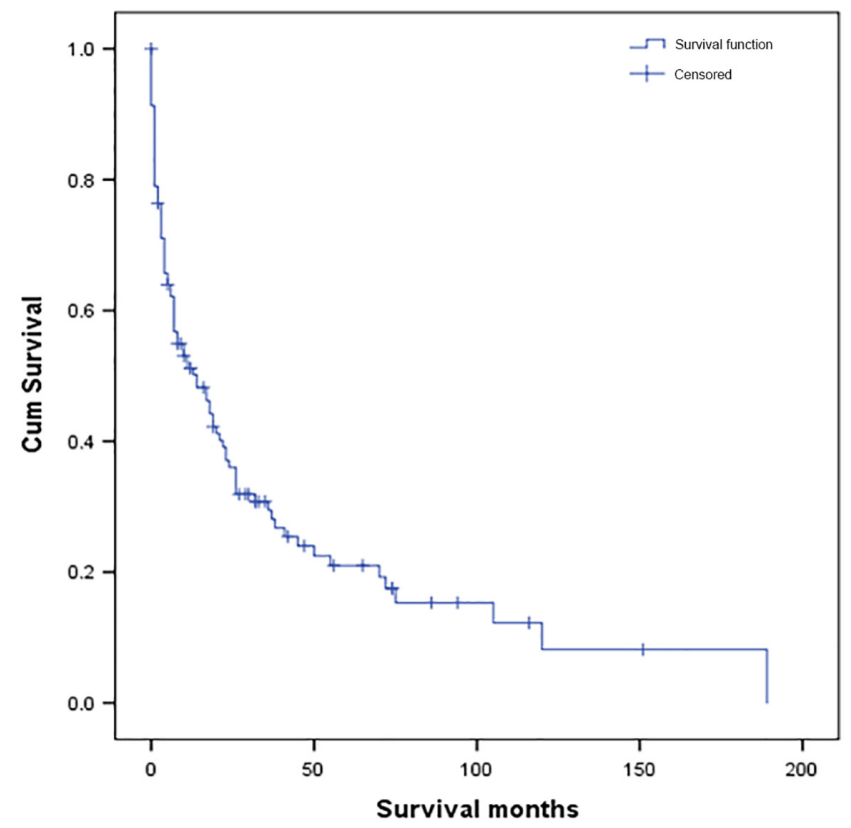

Figure 2

Overall survival (OS) of patients of second adrenal gland tumor, SEER (1992-2013). https://ec.bioscientifica.com

https://doi.org/10.1530/EC-18-0304
(C) 2018 The authors Published by Bioscientifica Ltd This work is licensed under a Creative Commons
Attribution-NonCommercial 4.0 International License. 
low numbers may be falsely positive, as we could not adjust $P$-values to do a multiple significance testing. In case of breast cancers, BRCA1 or BRCA2 mutations are the main causes of breast cancer (9). Although there are 28 breast cancer patients $(23.7 \%)$ in our cohort that develop adrenal gland tumor as a second malignancy, there are only 3 case reports in literature $(10,11)$ that showed association between adrenal gland tumors and BRCA1 or BRCA2 mutations. These genetic associations should be investigated in large longitudinal study of primary breast cancer and adrenal gland tumor as a second malignancy.

The incidence of adrenocortical carcinomas (ACCs) as a first primary tumor is the highest in adults aged between 40 and 50 years, but the tumor can appear at any age (12). The molecular pathway analysis of ACC using next-generation sequencing leads to identification of key modulators that impact adrenocortical tumorigenesis (13). Genetic mutations for example TP53 and CTNNB1 play role as a tumor driver in ACC (13). Also, TP53 genetic mutation contributes to $40-50 \%$ of all human tumors $(14,15,16,17)$. In our cohort, ACC represents about $50 \%$ of all patients with second primary adrenal gland malignancy. Therefore, shared genetic mechanism, which may attribute to TP53 or CTNNB1, may explain this high incidence. However, ACC's high incidence cannot be explained in the absence of data on etiology of adrenal gland tumor and other genetic and non-genetic risk factors.

The risk of developing an adrenal malignancy as a second primary was higher than a first primary, taking into consideration the rarity of adrenal malignancies, and the sustained decline of cancer mortality in the United States that started from early and mid-1990s (18), which may play a role in increasing the risk of developing a subsequent cancer among primary cancers survivors. However, racial disparities should also be taken into consideration. Cancer mortality among blacks is higher than that among whites in the United States $(19,20,21)$. This could explain that the risk of developing an adrenal cancer as an SPM was higher among whites. It is worthy to refer in this context that there were no reported cases of the event from Alaska Natives registry although there was high incidence of cancer reported from this registry (22). This may be explained based on the higher mortality rate in general among Alaska natives (23) and poor cancer survival rate among this race group in particular (24). Racial disparities in cancer incidence and mortality in the United States are a big challenge that require collaborative efforts for better cancer control (25).
In addition, the long-term effects of chemotherapy could explain the high incidence of second malignancy among white survivors in addition to the increasing incidence in elder cancer survivors found in SEER study. This is also confirmed by published reports from the two cancer types found in this study as the most common first primary tumor site (prostate $(26)$ and breast $(27,28)$.

It is known that using imatinib, tyrosine kinase inhibitors (TKIs), as a standard treatment of CML started from the beginning of the millennium. There were many reports about second malignancies after imatinib therapy in CML patients $(29,30,31)$; none of them included adrenal gland tumors as second malignancy. The carcinogenic effect of imatinib on adrenal gland was only available from animal model (32). Our results showed only one case of adrenal gland malignancy after CML. However, we should take into consideration that we included patients from 1992 to 2013. So, it is difficult to be correlated to the carcinogenic biology of CML itself or old treatment modalities used before TKIs era or imatinib itself.

In general, there are many risk factors that affect the development of a second malignancy in cancer survivors. Late side effects of treatment modalities used (chemotherapy and radiotherapy) are one of these risk factors. Other risk factors include genetic factors, lifestyle, microenvironment of primary tumor and attained age. All these factors may affect the latency period difference. In our sample, most events occurred within 4 years of diagnosis of the first malignancy. This may indicate that the increased risk of the second malignancy may be more of a direct, relatively short-term effect of the first malignancy itself, or treatment modalities used. Enhancement of follow-up programs for cancer survivors in any cancer center is the best approach for detection of other underreported second malignancies.

Although the results of this study showed high incidence of adrenal gland tumor in the left side but such results cannot be generalized as the tumor is rare and most data were published in the form of case reports or case series $(33,34,35)$. In general, there were no systematic reviews about incidence of adrenal gland tumor in relation to laterality.

Our sample included four cases who had first and second primary adrenal gland tumors of the same histology (8370/3: adrenal cortical carcinoma). It is difficult to do any statistical analysis and make a conclusion from four cases only. However, we noticed that the latencies between the first and second adrenal gland tumor in these four cases were reasonably long (21-175 months).

This work is licensed under a Creative Commons Attribution-NonCommercial 4.0 International License. 
Neuroblastoma is the third most common malignancy in pediatrics, but little is known about neuroblastoma as a second primary tumor (36). In SEER database, there was only one patient who developed second primary neuroblastoma (9490/3: ganglioneuroblastoma) at the first year of life after first primary brain tumor.

Considering two patients with clear cell adenocarcinoma and renal cell carcinoma, There were many published reports about the presence of cancer metastasis from renal tumor to adrenal gland $(37,38$, 39 ), and we recommend future thorough analysis of such findings to avoid inaccurate reporting of site.

Another note for the patient reported with two incidence of adrenal gland tumor (left then right) in the same month. It is difficult to consider the second event in the right adrenal as a metachronus cancer or second malignancy. It would be clinically helpful to do a revision of the radiological imaging of this patient. As the two incidences occurred in the same month, this increased the probability of initial bilateral adrenal gland tumor especially both had the same histology subtype.

There are many limitations in our study. Lack of data about etiology of adrenal gland malignancies and other cancer risk factors is one of them. Another potential limitation is the retrospective nature of the study and the use of SEER registries, which could have unreliable coding for rare histologies and possibly misdiagnoses (40). This possibility of misdiagnoses arises due to the fact that while pathological diagnosis of adrenal tumor is often difficult and needs specific expertise, diagnoses recorded in SEER are done by different pathologists without central revision. Also, SEER database did not release information about the chemotherapy in their basic database. Moreover, radiation and chemotherapy information are not well-covered in the SEER database, and recently, they advised not to use it to compare groups due to its low sensitivity (41). These limitations make it necessary to be cautious when reaching a conclusion. However, there are some strengths including the large number of subjects recruited, the long duration of follow-up of most cases and the high level of ascertainment of the incidence of the event.

\section{Conclusion}

Little is available in the literature about adrenal gland tumors as second primary tumors. Its incidence is high in white race cancer survivors in the United States. The risk of cancer survivors suffering from a second primary

https://ec.bioscientifica.com
https://doi.org/10.1530/EC-18-0304 2018 The authors

adrenal gland tumor should receive more attention in the US. This would ideally be through follow-up programs at specialized national cancer networks, especially for rare tumors like adrenal gland.

\section{Declaration of interest}

The authors declare that there is no conflict of interest that could be perceived as prejudicing the impartiality of the research reported.

\section{Funding}

A S A is supported by grant 57147166 from The German Academic Exchange Service (DAAD).

\section{Ethical approval and informed consent}

Neither was required because the data were anonymized datasets made available by SEER program, National Cancer Institute.

\section{Author contribution statement}

W M R and A S A have designed the concept of the paper. A S A has conducted the analysis of the data and has access to it. W M R, A S A, A S, M A, A M G, A M, A M A, A E and M A A have contributed to data interpretation and writing the paper. All authors have revised and agreed to the content of the paper.

\section{Acknowledgement}

The authors would like to thank Mohamed-Ismail Rakha for his efforts in revising the manuscript.

\section{References}

1 Correa P \& Chen VW. Endocrine gland cancer. Cancer 199575 338-352. (https://doi.org/10.1002/1097-0142(19950101) 75:1+<338::AID-CNCR2820751316>3.0.CO;2-F)

2 Lee JE, Evans DB, Hickey RC, Sherman SI, Gagel RF, Abbruzzese MC, Abbruzzese JL \& Abbruzzese MD. Unknown primary cancer presenting as an adrenal mass: frequency and implications for diagnostic evaluation of adrenal incidentalomas. Surgery 1998124 1115-1122. (https://doi.org/10.1067/ msy.1998.92009)

3 Babinska A, Peksa R, Swiątkowska-Stodulska R \& Sworczak K. The collection of five interesting cases of adrenal tumors from one medical center. World Journal of Surgical Oncology 201412377. (https://doi.org/10.1186/1477-7819-12-377)

4 Ho LM, Paulson EK, Brady MJ, Wong TZ \& Schindera ST. Lipid-poor adenomas on unenhanced CT: does histogram analysis increase sensitivity compared with a mean attenuation threshold? American Journal of Roentgenology 2008191 234-238. (https://doi.org/10.2214/ AJR.07.3150)

5 Wasserman JD, Novokmet A, Eichler-Jonsson C, Ribeiro RC, Rodriguez-Galindo C, Zambetti GP \& Malkin D. Prevalence and functional consequence of TP53 mutations in pediatric adrenocortical carcinoma: a Children's Oncology Group study. Journal of Clinical Oncology 201533 602-609. (https://doi. org/10.1200/JCO.2013.52.6863) 
6 Suzuki H. Laparoscopic adrenalectomy for adrenal carcinoma and metastases. Current Opinion in Urology 200616 47-53. (https://doi. org/10.1097/01.mou.0000193378.14694.9b)

7 VanderWalde AM \& Hurria A. Second malignancies among elderly survivors of cancer. Oncologist 201116 1572-1581. (https://doi. org/10.1634/theoncologist.2011-0214)

8 Bhatia S \& Sklar C. Second cancers in survivors of childhood cancer. Nature Reviews Cancer 20022 124-132. (https://doi.org/10.1038/ nrc722)

9 Toland AE \& Andreassen PR. DNA repair-related functional assays for the classification of BRCA1 and BRCA2 variants: a critical review and needs assessment. Journal of Medical Genetics 201754 721-731. (https://doi.org/10.1136/jmedgenet-2017-104707)

10 Barak F, Shiri-Svredlov R, Sade B-BR, Kruglikova A, Friedman E, BenDor D \& Goldberg I. Adrenal tumors in BRCA1/BRCA2 mutation carriers. American Journal of Medical Genetics 200198 277-279. (https://doi.org/10.1002/1096-8628(20010122)98:3<277::AIDAJMG1082>3.0.CO;2-Q)

11 El Ghorayeb N, Grunenwald S, Nolet S, Primeau V, Côté S, Maugard CM, Lacroix A, Gaboury L \& Bourdeau I. First case report of an adrenocortical carcinoma caused by a BRCA2 mutation. Medicine 201695 e4756. (https://doi.org/10.1097/ MD.0000000000004756)

12 Olaku OO \& Taylor EA. Cancer in the medically underserved population. Primary Care 201744 87-97. (https://doi.org/10.1016/j. pop.2016.09.020)

13 Lodish M. Genetics of adrenocortical development and tumors. Endocrinology and Metabolism Clinics of North America 201746 419-433. (https://doi.org/10.1016/j.ecl.2017.01.007)

14 Olivier M, Goldgar DE, Sodha N, Ohgaki H, Kleihues P, Hainaut P \& Eeles RA. Li-Fraumeni and related syndromes: correlation between tumor type, family structure, and TP53 genotype. Cancer Research $2003636643-6650$.

15 Kandoth C, McLellan MD, Vandin F, Ye K, Niu B, Lu C, Xie M, Zhang Q, McMichael JF, Wyczalkowski MA, et al. Mutational landscape and significance across 12 major cancer types. Nature 2013 502 333-339. (https://doi.org/10.1038/nature12634)

16 Said R, Hong DS, Warneke CL, Lee JJ, Wheler JJ, Janku F, Naing A, Falchook GS, Fu S, Piha-Paul S, et al. p53 mutations in advanced cancers: clinical characteristics, outcomes, and correlation between progression-free survival and bevacizumab-containing therapy. Oncotarget 20134 705-714. (https://doi.org/10.18632/ oncotarget.974)

17 Muller PAJ \& Vousden KH. Mutant p53 in cancer: new functions and therapeutic opportunities. Cancer Cell 201425 304-317. (https://doi. org/10.1016/j.ccr.2014.01.021)

18 Weir HK, Thun MJ, Hankey BF, Ries LAG, Howe HL, Wingo PA, Jemal A, Ward E, Anderson RN \& Edwards BK. Annual report to the nation on the status of cancer, 1975-2000, featuring the uses of surveillance data for cancer prevention and control. Journal of the National Cancer Institute 200395 1276-1299. (https://doi. org/10.1093/jnci/djg040)

19 Henley SJ, Singh S, King J, Wilson R, Ryerson B \& Centers for Disease Control and Prevention (CDC). Invasive cancer incidence - United States, 2010. Morbidity and Mortality Weekly Report 201463 253-259.

20 Henley SJ, Singh SD, King J, Wilson RJ, O’Neil ME \& Ryerson AB. Invasive cancer incidence and survival - United States, 2013. Morbidity and Mortality Weekly Report 201766 69-75. (https://doi. org/10.15585/mmwr.mm6603a1)

21 Henley SJ, Singh SD, King J, Wilson RJ, O’Neil ME \& Ryerson AB. Invasive cancer incidence and survival - United States, 2012. Morbidity and Mortality Weekly Report 201564 1353-1358. (https:// doi.org/10.15585/mmwr.mm6449a1)

22 Foote M, Strickland R, Lucas-Pipkorn S, Williamson A \& Lamers L. The high burden of cancer among American Indians/Alaska natives in Wisconsin. World Mycotoxin Journal 2016115 11-16.
23 Andrews MM \& Krouse SA. Research on excess deaths among American Indians and Alaska Natives: a critical review. Journal of Cultural Diversity 19952 8-15.

24 Mahoney MC \& Michalek AM. The health status of American Indians and Alaska Natives: 2. Lessons for cancer educators. Journal of Cancer Education 199914 23-27. (https://doi. org/10.1080/08858199909528569)

25 Olaku OO \& Taylor EA. Cancer in the medically underserved population. Primary Care 201744 87-97. (https://doi.org/10.1016/j. pop.2016.09.020)

26 Benjamins MR, Hunt BR, Raleigh SM, Hirschtick JL \& Hughes MM. Racial disparities in prostate cancer mortality in the 50 Largest US cities. Cancer Epidemiology 201644 125-131. (https://doi. org/10.1016/j.canep.2016.07.019)

27 DeSantis CE, Fedewa SA, Goding Sauer A, Kramer JL, Smith RA \& Jemal A. Breast cancer statistics, 2015: convergence of incidence rates between black and white women. CA: A Cancer Journal for Clinicians 201666 31-42. (https://doi.org/10.3322/caac.21320)

28 Iqbal J, Ginsburg O, Rochon PA, Sun P \& Narod SA. Differences in breast cancer stage at diagnosis and cancer-specific survival by race and ethnicity in the United States. JAMA 2015313 165-173. (https:// doi.org/10.1001/jama.2014.17322)

29 Gunnarsson N, Stenke L, Höglund M, Sandin F, Björkholm M, Dreimane A, Lambe M, Markevärn B, Olsson-Strömberg U, Richter J, et al. Second malignancies following treatment of chronic myeloid leukaemia in the tyrosine kinase inhibitor era. British Journal of Haematology 2015169 683-688. (https://doi.org/10.1111/ bjh.13346)

30 Duman BB, Paydas S, Disel U, Besen A \& Gurkan E. Secondary malignancy after imatinib therapy: eight cases and review of the literature. Leucemia and Lymphoma 201253 1706-1708. (https://doi. org/10.3109/10428194.2012.666545)

31 Budrukkar A, Muttagi S, Shahid T, Chatturvedi P, Banavali S, Laskar SG, Murthy V, D'Cruz A \& Agarwal JP. Second primary head and neck squamous cell cancers with aggressive behavior in patients with chronic myeloid leukaemia. British Journal of Oral and Maxillofacial Surgery 201250 504-507. (https://doi.org/10.1016/j. bjoms.2011.08.012)

32 Roszkiewicz F, Garidi R, Vaida I, Royer B, Parcelier A, Marolleau JP \& Damaj G. Tyrosine kinase inhibitors and solid tumours: case report and review of the literature. Pharmacology 200984 38-41. (https:// doi.org/10.1159/000225970)

33 Rashed WM, Zekri W, Awad M, Taha H, Abdalla B \& Alfaar AS. Nonfunctioning adrenocortical carcinoma in pediatric acute lymphoblastic leukemia: a case report of a Rare Multiple Primaries Combination. Journal of Pediatric Hematology/Oncology 201739 150-152. (https://doi.org/10.1097/MPH.0000000 000000699)

34 Koga H, Naito S, Hasegawa S, Tamada K, Kuroiwa K, Hara R, Harano M, Furukawa M \& Kumazawa J. Clinical review of 105 cases of adrenal tumor, with special reference to incidental tumor. Nihon Hinyokika Gakkai Zasshi 199687 915-922. (https://doi.org/10.5980/ jpnjurol1989.87.915)

35 Salomon L, Soulié M, Mouly P, Saint F, Cicco A, Olsson E, Hoznek A, Antiphon P, Chopin D, Plante P, et al. Experience with retroperitoneal laparoscopic adrenalectomy in 115 procedures. Journal of Urology 2001166 38-41. (https://doi.org/10.1016/S00225347(05)66071-5)

36 Irwin MS \& Park JR. Neuroblastoma: paradigm for precision medicine. Pediatric Clinics of North America 201562 225-256. (https://doi.org/10.1016/j.pcl.2014.09.015)

37 Ertl CW \& Darras FS. Solitary metachronous contralateral adrenal metastasis from renal cell carcinoma. Urology 199954 162. (https:// doi.org/10.1016/S0090-4295(98)00565-2)

38 Yamasaki Y, Koga S, Nishikido M, Noguchi M, Kanetake H \& Saito Y. The role of surgery in renal cell carcinoma with solitary

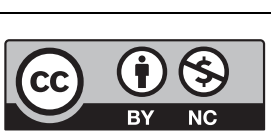

This work is licensed under a Creative Commons Attribution-NonCommercial 4.0 International License. 
metachronous metastasis to contralateral adrenal gland. Anticancer Research 19 5575-5576.

39 Kessler OJ, Mukamel E, Weinstein R, Gayer E, Konichezky

M \& Servadio C. Metachronous renal cell carcinoma metastasis

to the contralateral adrenal gland. Urology $1998 \mathbf{5 1}$

539-543. (https://doi.org/10.1016/S0090-4295(97) 00698-5)
$40 \mathrm{Yu}$ JB, Gross CP, Wilson LD \& Smith BD. NCI SEER public-use data: applications and limitations in oncology research. Oncology 200923 288-295.

41 Noone AM, Lund JL, Mariotto A, Cronin K, McNeel T, Deapen D \& Warren JL. Comparison of SEER treatment data with medicare claims. Medical Care 201654 e55-e64. (https://doi.org/10.1097/ MLR.0000000000000073

Received in final form 2 August 2018

Accepted 20 August 2018

Accepted Preprint published online 23 August 2018 https://ec.bioscientifica.com

https://doi.org/10.1530/EC-18-0304
() 2018 The authors Published by Bioscientifica Ltd

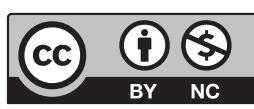

This work is licensed under a Creative Commons Attribution-NonCommercial 4.0 International License. 